\title{
Hêliconias como alternativa econômica para comunidades amazônicas
}

\author{
Rafael ARRUDA ${ }^{1 *}$, Vinícius Tadeu de CARVALHO², Paulo César Machado ANDRADE \\ Maria Goretti PINTO ${ }^{4}$
}

RESUMO

Reservas extrativistas (RESEX) são espaços territoriais destinados à exploração sustentável e conservação dos recursos naturais renováveis, por populações extrativistas. Além disso, tem como finalidade implantar alternativas de renda que contribuam para a melhoria das condiçóes de vida das famílias locais. Dentre as variadas possibilidades de renda pelas comunidades que compóem as RESEX, destacamos neste trabalho o uso das helicônias. As espécies de Heliconia são um dos mais vistosos grupos de plantas herbáceas das florestas tropicais. Entretanto seu uso como fonte de renda é desconhecido pelas comunidades que compóem a RESEX. Registramos 11 espécies de Heliconia na RESEX do Baixo Juruá com uso potencial como plantas ornamentais: $H$. acuminata, $H$. densiflora, $H$. hirsuta, $H$. lasiorachis, $H$. stricta, $H$. chartacea, $H$. juruana, $H$. marginata, $H$. psittacorum, $H$. spathocircinata e $H$. tenebrosa. Atualmente o mercado de plantas ornamentais está em expansão no Brasil, mas a Amazônia parece não estar acompanhando este processo, demonstrando falta de iniciativa política. A economia na forma do extrativismo praticada dentro das reservas florestais na Amazônia, mesmo acarretando alguns impactos diretos sobre a fauna e a flora, ajuda a manter as funções ecológicas originais da floresta evitando perdas futuras de biodiversidade regional. Adicionalmente, garante a continuidade das populaçóes tradicionais no campo, com efeito direto na economia local e regional.

PALAVRAS-CHAVE: Ervas de sub-bosque, sustentabilidade, conservação, plantas ornamentais, RESEX.

\section{Heliconias of the Baixo Juruá Extractive Reserve: economical potential for Amazonian traditional population}

\section{ABSTRACT}

Extractive Reserves (Reservas Extrativistas-RESEX, in portuguese) are defined as territorial spaces destined for auto-sustainable exploration and conservation of renewable natural resources for the traditional population. Moreover, they are an alternative source of income for improving life conditions of the local families. Amongst the possibilities of income for the communities that make up the RESEX, which we discuss, is the use of Heliconia understorey herbs. The Heliconia genus is one of the colorful groups of tropical forest non-timber plants. However, as an income source, it is unknown to the RESEX communities. We registered 11 species of Heliconia in the Baixo Juruá Extractive Reserve with potential as ornamental plants: H. acuminata, $H$. densiflora, $H$. hirsuta, $H$. lasiorachis, $H$. stricta, $H$. chartacea, $H$. juruana, $H$. marginata, $H$. psittacorum, $H$. spathocircinata and $H$. tenebrosa. Currently in Brazil, the commercialization of ornamental plants is expanding, but the Amazonian region seems not to be following this trend, demonstrating perhaps lack of political initiative. Even though it causes some impact on fauna an flora, the practice of extractive economy inside the forest reserves in Amazonia helps keep the ecological functions of the forest intact, preventing future losses of regional biodiversity. Additionally, it guarantees the continuity of traditional populations in the natural areas, with direct effect on the local and regional economy.

KEYWORDS: Understorey herbs, sustainability, conservation, ornamental plants, RESEX.

\footnotetext{
1 Coordenação de Pesquisas em Ecologia, Instituto Nacional de Pesquisas da Amazônia, 69011-970, CP 478, Manaus, AM

2 Coleção de Anfíbios e Répteis, Campus II, Instituto Nacional de Pesquisas da Amazônia, 69011-970, CP 478, Manaus, AM

3 Departamento de Produção Animal e Vegetal, Faculdade de Ciências Agrárias, Universidade Federal do Amazonas, 69077-000, Manaus, AM

${ }^{4}$ Instituto Brasileiro do Meio Ambiente e dos Recursos Naturais Renováveis (IBAMA), Gerência do Ibama em Tefé, Estrada do Aeroporto, 725, Centro, 69470-000, Tefé, AM

* Autor para correspondência: rsarruda@yahoo.com.br
} 


\section{INTRODUÇÃO}

Reserva Extrativista (RESEX) é uma Unidade de Conservação de uso sustentável e integra o Sistema Nacional de Unidades de Conservação (SNUC). É definida como uma área utilizada por populações extrativistas tradicionais, cuja subsistência baseia-se no extrativismo, na agricultura de subsistência e na criação de animais de pequeno porte. Tem como objetivos básicos proteger os meios de vida e a cultura dessas populações, além de assegurar o uso sustentável dos recursos naturais da unidade (SNUC, Lei 9985/2000).

As RESEXs surgiram como uma reivindicação dos trabalhadores rurais extrativistas, principalmente seringueiros, que tinham na regularização fundiária de suas terras, condição necessária para a consolidação de suas atividades econômicas (Rodrigues et al., 2004). Pelo fato destas atividades econômicas serem direcionadas à exploração de produtos oriundos do ecossistema nativo, membros dos movimentos ambientalistas apoiaram este modo de produção, que ficou conhecido como Extrativismo (Rodrigues et al., 2004). Deste modo, as RESEXs ganharam atenção internacional por causa do seu significado para o desenvolvimento sustentável, principalmente em regiōes de grande diversidade e que estão sofrendo pressão antrópica, como a Floresta Amazônica.

Existem atualmente 53 RESEXs Federais, a maioria localizada na região amazônica, e outras 120 estão em processo de criação (DISAM, IBAMA, comunicação pessoal). A RESEX do Baixo Juruá foi criada pelo Decreto de $1^{\circ}$ de agosto de 2001, na região do baixo Rio Juruá, Estado do Amazonas. Atualmente encontra-se em processo de elaboração o Plano de Manejo da RESEX, para o qual já foram realizados diagnósticos do meio abiótico e biótico da área além da caracterização sócio-econômica da população residente, usando métodos participativos, coleta de dados primários e secundários, por equipes multidisciplinares, coordenadas pelo IBAMA do Estado do Amazonas. Um dos objetivos deste Plano de Manejo é identificar atividades e/ou produtos que possam, potencialmente, ser utilizados de forma sustentável, gerando renda e melhoria das condições de vida da população local. Dentre os produtos já levantados, ressalta-se as helicônias, com razoável potencial econômico.

As espécies de Heliconia (Heliconiaceae) são um dos mais vistosos grupos de plantas herbáceas das florestas tropicais (Berry \& Kress, 1991). Elas apresentam uma ampla variação dos caracteres florais, bem como, diferem em distribuição e adaptação ao cultivo (Berry \& Kress, 1991). No México, por exemplo, já existem projetos envolvendo seu cultivo e comercialização como plantas ornamentais (Hernández, 2004), contribuindo para futuros programas de manejo que relevem a exploração sustentável e a conservação dessas espécies a longo prazo. Em nível mundial, estima-se que a produção comercial de helicônias esteja em torno de 21 milhóes de dólares (Hernández, 2004). Países como Holanda, Estados Unidos e Itália são atualmente os maiores importadores de flores tropicais brasileiras (Junqueira \& Peetz, 2007). Em 2005, na RESEX do Baixo Juruá foi realizado um diagnóstico participativo, com a finalidade de fundamentar a elaboração do Plano de Manejo. Neste evento, as helicônias foram citadas por terem as suas palhas utilizadas na construção das casas dos moradores. Este fato é um relato da subutilização dos recursos naturais disponíveis na região, pois as helicônias são valorizadas nos mercados de plantas ornamentais e floricultura.

O objetivo deste trabalho foi realizar um levantamento das helicônias ocorrentes na RESEX do Baixo Juruá, bem como discutir o potencial do grupo para a geração de renda.

\section{MATERIAL E MÉTODOS}

\section{ÁREA DE ESTUDO}

A Reserva Extrativista do Baixo Juruá possui área de 188.000 ha, limitando-se com os Rios Copacá ao Leste, Juruá a Oeste e Andirá ao Sul, localizando-se nos Municípios de Juruá e Uarini, Estado do Amazonas, Brasil. O acesso é feito pela cidade de Juruá, localizada na região do baixo Rio Juruá, na margem direita. A RESEX possui 13 comunidades, ao longo dos Rios Juruá e Andirá, nos ecossistemas de terra firme e várzea (alta e baixa) (Figura 1). O Rio Juruá é o mais sinuoso da Bacia Amazônica. A largura média é de $140 \mathrm{~m}$, sendo que nos trechos retos varia de 100 a $200 \mathrm{~m}$, e nas curvas acentuadas, de 80-120 m. A variação do nível das águas entre uma enchente e a vazante consecutiva pode atingir até 24,5 m (Goulding et al., 2003).

\section{COLETA DE DADOS}

O trabalho de campo foi realizado nos meses de maio e junho de 2006 e maio de 2007. Na primeira excursão, as áreas próximas às 13 comunidades que compõem a RESEX com acesso pelo Rio Juruá foram percorridas de barco, para registro das espécies de helicônias. Para amostrar as áreas de terra firme através da floresta alagada, localmente chamada de igapó, foram realizadas caminhadas em trilhas de acesso à floresta feitas pelos moradores. Na segunda excursão, foi percorrido de barco aproximadamente $40 \%$ do limite leste da RESEX, pelo Rio Copacá, para registro das espécies de helicônias. Além disso, foi amostrada uma trilha em terra firme, de 2,1 km, acessada através do igarapé São Benedito. Todas as helicônias registradas foram georeferenciadas com auxílio de GPS e fotografadas com máquina digital. A identificação das espécies de helicônias foi iniciada em campo, comparando as fotos obtidas com guias de campo disponíveis (Berry \& Kress, 1991; Kress et al. 1999), sendo adicionalmente consultado um especialista para confirmação e correta identificação das espécies. Não foi coletada amostra 


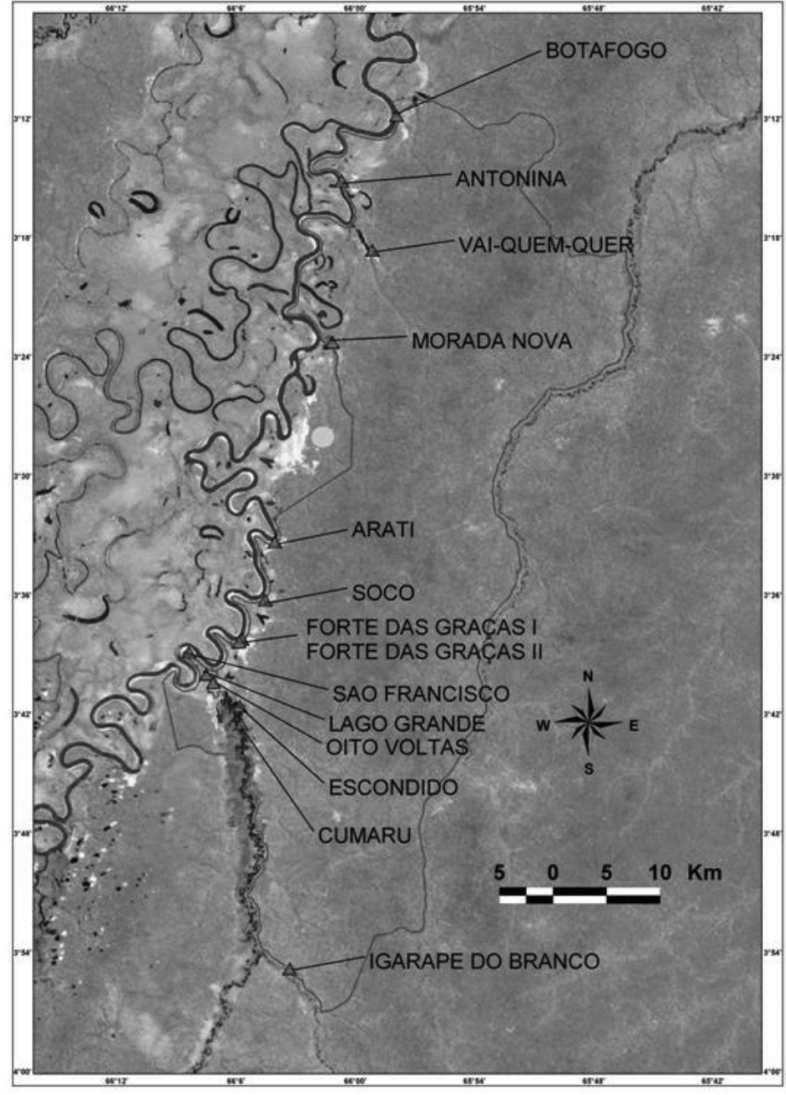

Figura 1 - Localização das comunidades que compõem a Reserva Extrativista do Baixo Juruá. Círculo indica o município de Juruá. para herbário, mas o material fotográfico pode ser solicitado para o primeiro autor.

\section{RESULTADOS}

Na RESEX foram registradas 11 espécies de Heliconia: Heliconia acuminata, $H$. densiflora, $H$. hirsuta, $H$. lasiorachis, H. stricta (Figura 2), H. chartacea, H. juruana, H. marginata, H. psittacorum, H. spathocircinata e H. tenebrosa (Figura 3). As espécies que ocorreram em terra firme foram $H$. acuminata, $H$. chartacea, $H$. densiflora, $H$. lasiorachis e H. tenebrosa. Heliconia spathocircinata foi encontrada nas margens de um igarapé de terra firme, localizado nas proximidades do Rio Copacá. As espécies $H$. hirsuta, $H$. stricta, $H$. juruana, $H$. marginata e $H$. psittacorum ocorreram principalmente nas margens do Rio Juruá. Na margem do Rio Copacá foi encontrada apenas H. psittacorum. Como não foi possível amostrar a totalidade da RESEX, é provável que o aumento do esforço amostral propicie que outras espécies sejam registradas na região.

As 11 espécies de Heliconia foram identificadas e descritas com base em Aristeguieta (1961), Berry \& Kress (1991) e Kress et al. (1999).

Heliconia acuminata A.Rich. (Figura 2A) - erva musóide, ca. 1 $\mathrm{m}$ altura; folhas com pecíolo $8-45 \mathrm{~cm}$ de comprimento, lâmina $35-75 \times 7-17 \mathrm{~cm}$, com nervura central marrom; inflorescência ereta, brácteas vermelhas e flores brancas.

Heliconia densiflora B.Verl. (Figura 2B) - erva musóide, ca. $2 \mathrm{~m}$ altura; folhas com pecíolo variando de $3,5-30 \mathrm{~cm}$ de comprimento, lâmina $19-45$ x 5-18 cm; inflorescência ereta, brácteas vermelho-alaranjadas e flores alaranjadas.
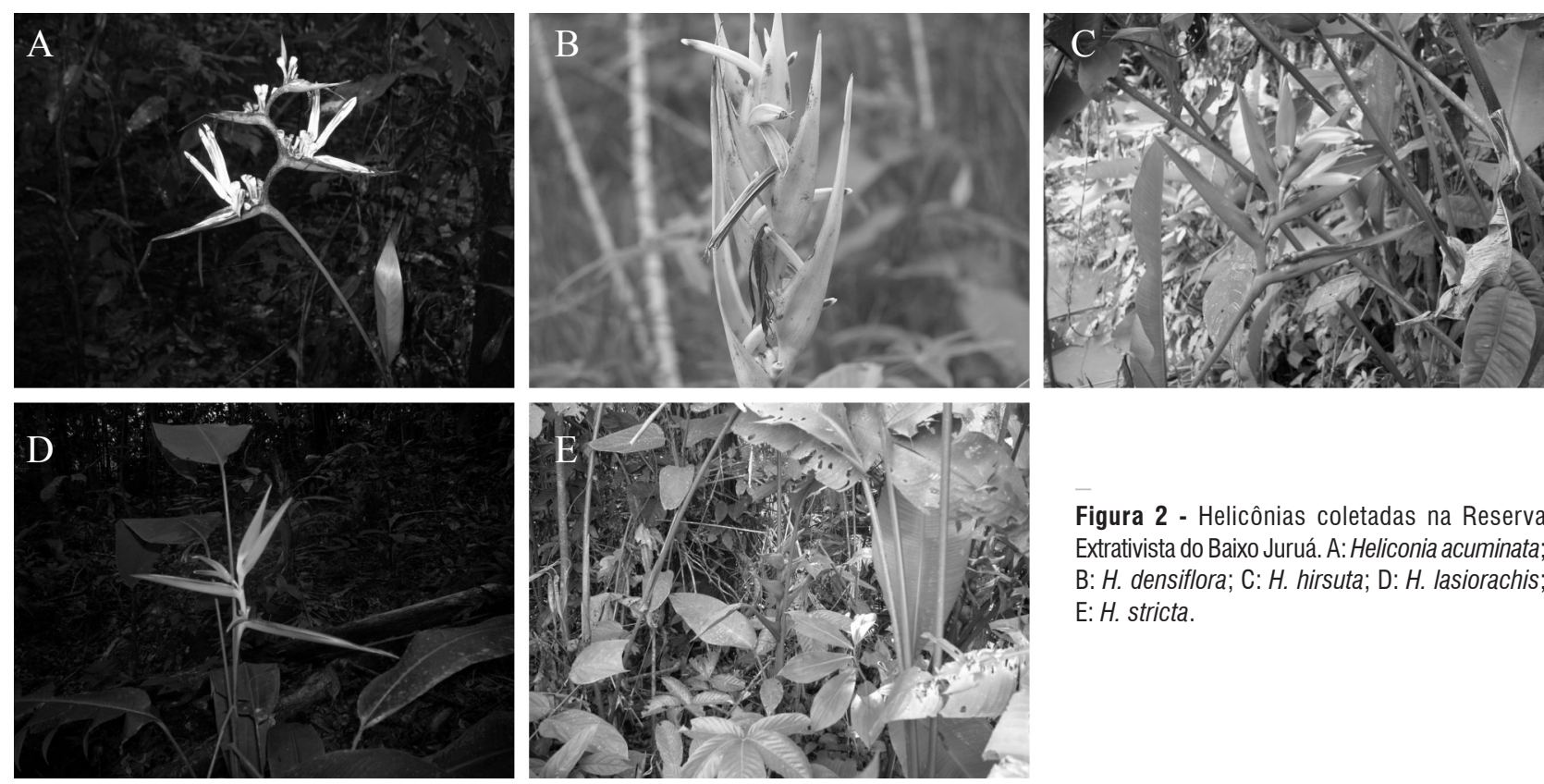

Figura 2 - Helicônias coletadas na Reserva Extrativista do Baixo Juruá. A: Heliconia acuminata; B: H. densiflora; C: H. hirsuta; D: H. lasiorachis; E: H. stricta. 
Heliconia hirsuta L.f. (Figura 2C) - erva zingiberóide, ca. $4 \mathrm{~m}$ altura; folhas com pecíolo $0,5-1 \mathrm{~cm}$ de comprimento, lâmina $38-40$ x 11-14 cm; inflorescência ereta, brácteas vermelhas e flores alaranjadas com uma mácula distal preta.

Heliconia lasiorachis L. Andersson (Figura 2D) - erva canóide, ca. $2 \mathrm{~m}$ altura; folhas com pecíolo $35-70 \mathrm{~cm}$ de comprimento, lâmina 35-39 x 11-15 cm; inflorescência ereta, brácteas avermelhadas com base verde e flores verdes com uma mácula irregular distal verde-escura.

Heliconia stricta Huber (Figura 2E) - erva musóide, ca. 4 m altura; folhas com pecíolo 45-102 cm de comprimento, lâmina 85-165 x 22-30 cm; inflorescência ereta, brácteas vermelhas e flores verdes.
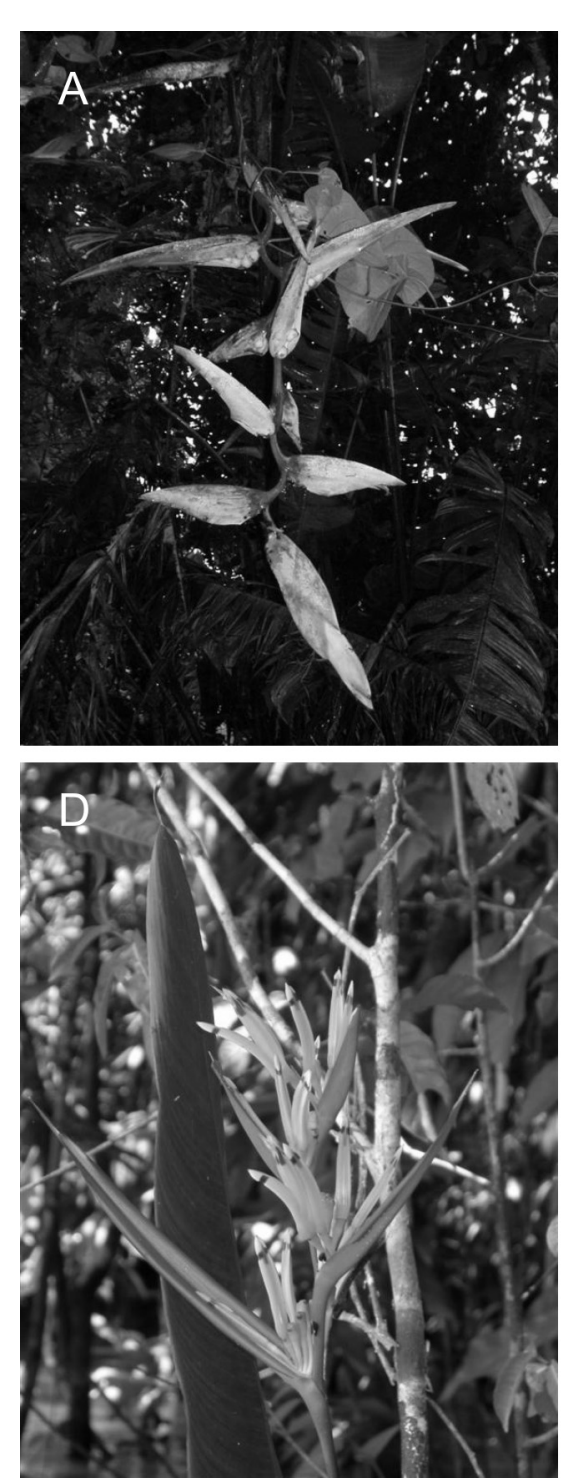

Heliconia chartacea Lane ex Souza Barreiros (Figura 3A) - erva musóide, ca. 4,5-6 m altura; folhas com pecíolo $26-55 \mathrm{~cm}$ de comprimento, lâmina 85-130 x 24-32 cm e; inflorescência pendente, brácteas escarlates e flores verdes.

Heliconia juruana Loes. (Figura 3B) - erva canóide, ca. 4 $\mathrm{m}$ altura; folhas com pecíolo $8,5-13 \mathrm{~cm}$ de comprimento, lâmina 75-85 x 13,5-18 cm; inflorescência pendente, brácteas vermelhas na base e amareladas na região distal e flores amareladas com base verde.

Heliconia marginata Pittier (Figura 3C) - erva musóide, ca. $4 \mathrm{~m}$ altura; folhas com pecíolo $45-90 \mathrm{~cm}$ de comprimento, lâmina $60-120$ x 17-25 cm; inflorescência pendente, brácteas vermelhas com regiáo distal amarelada e flores amarelas.
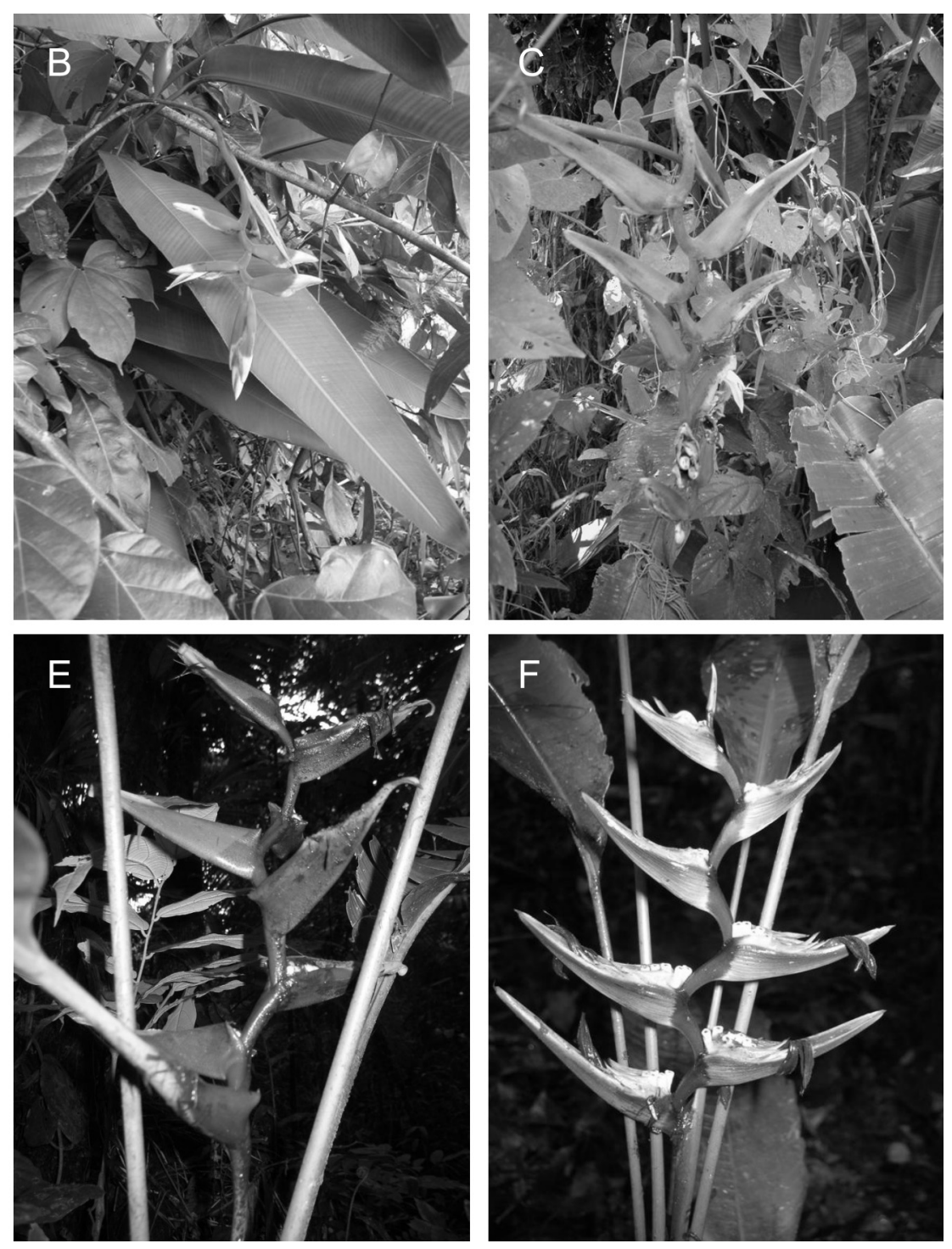

Figura 3 - Helicônias coletadas na Reserva Extrativista do Baixo Juruá. A: Heliconia chartacea; B: H. juruana; C: H. marginata; D: H. psittacorum; E: H. spathocircinata; F: H. tenebrosa. 
Heliconia psittacorum L.f. (Figura 3D) - erva musóide, ca. 2 m altura; folhas com pecíolo $11-32 \mathrm{~cm}$ de comprimento, lâmina $37-60$ x 6-10 cm; inflorescência ereta, brácteas vermelhas com região proximal alaranjada e flores alaranjadas.

Heliconia spathocircinata Aristeg. (Figura 3E) - erva musóide, ca. 2,5 m altura; folhas com pecíolo $50-71 \mathrm{~cm}$ de comprimento, lâmina 85-110 x 25-30 cm; inflorescência ereta, brácteas vermelhas com região distal amarela e flores amarelas.

Heliconia tenebrosa J.F.Macbr. (Figura 3F) - erva musóide, ca. $1,5 \mathrm{~m}$ altura; folhas com pecíolo $13-55 \mathrm{~cm}$ de comprimento, lâmina 40-60 x 12-14 cm; inflorescência ereta, brácteas verdes e flores branca.

\section{DISCUSSÃO}

As espécies de helicônias encontradas na RESEX do Baixo Juruá apresentam grande variedade no tamanho e na coloração das inflorescências. Elas são relativamente fáceis de serem localizadas e são aparentemente abundantes nesta reserva, o que as qualifica como plantas ornamentais com potencial econômico. Entretanto, o conhecimento dos moradores locais a respeito do uso das helicônias como plantas ornamentais é inexistente. Os moradores desconhecem também seu uso no artesanato ou como plantas medicinais. As espécies de Heliconia são base de projetos econômicos usando variedades encontradas na natureza e híbridos obtidos em casa de vegetação (e.g. Hernández, 2004). Floricultura tropical é uma atividade em expansão como agronegócio gerador de renda, fixador de mão-de-obra no campo e adequado por ser cultura alternativa para a agricultura familiar.

$\mathrm{O}$ uso de produtos florestais não-madeireiros tem sido muito difundido nos últimos anos, principalmente como alternativa à extração de madeira, reduzindo o impacto na estrutura da floresta (Ticktin, 2004). Na Amazônia já existem estudos avaliando o impacto da colheita de ervas pela população tradicional e indígena e que são utilizadas no artesanato. No Arquipélago de Anavilhanas, Nakazono et al. (2004) realizaram um experimento simulando diferentes intensidades de extração do arumã, Ischnosiphon polyphyllus (Poepp. \& Endl.) Körn. (Marantaceae). Estes autores observaram que nas intensidades simuladas, a mortalidade de plantas adultas foi muito baixa. Entretanto, estes autores assinalaram a necessidade de outros estudos para balizar decisōes em relação ao manejo da espécie. No Parque Indígena do Xingu, Athayde et al. (2006) estudaram a etnoecologia de outra espécie de arumã, Ischnosiphon gracilis (Rudge) Körn. (Marantaceae). Estes autores, com base em experimentos de transplante de mudas para avaliar o crescimento do arumã em ambientes diferentes, sugeríram uma estratégia rotativa com intervalo de cinco anos de descanso para possibilitar a regeneração das populaçôes que sofreram colheitas, mas também sugeríram cuidado em extrapolar os resultados para outras espécies de arumã. Isto demonstra um crescente aumento do interesse na utilização de ervas para fins comerciais na Amazônia.

As helicônias oferecem potencial econômico que não está sendo explorado, e até este momento, pouco pesquisado. A possível explicação para a subutilização das helicônias na região é proveniente da dificuldade dos produtores rurais artesanais em percorrerem as cadeias produtivas sozinhos, sem parcerias comerciais (Guimarães, 2001). O que mais contribui para a falta de valor agregado em produtos oriundos das comunidades da Amazônia é a falta de infra-estrutura (Guimarães, 2001). Além disso, é necessária uma mudança na maneira de se fazer política na região. Os líderes políticos deveriam priorizar investimentos em iniciativas que darão maior retorno social e econômico com menor dano ambiental (Guimarães, 2001).

A falta de infra-estrutura e apoio logístico para escoamento da produção em áreas remotas como a RESEX do Baixo Juruá, são fatores limitantes para a atividade na região. O SEBRAE está trabalhando em nível nacional estimulando a criação de pólos de floricultura tropical. Em alguns destes Estados, como o Mato Grosso do Sul, existe apoio do PRONAF (Programa Nacional de Apoio à Agricultura Familiar) para estimular a atividade de floricultura comercial. Estudos mais detalhados das cadeias produtivas para a região amazônica ainda são raros, principalmente em regiôes mais distantes. Entretanto para que a filosofia de sustentabilidade das RESEXs possa garantir algum retorno financeiro para os comunitários, está prática deve ser estimulada. A cada ano mais reservas extrativistas são criadas, e a busca de mecanismos para estimular a permanência da mão de-de-obra no campo devem ser prioridade. Caso isto não ocorra, será apenas gasto de dinheiro e tempo.

A Amazônia pode ser considerada privilegiada em relação à potencialidade econômica de plantas ornamentais, devido à existência de uma flora bastante diversificada, pelo baixo custo de produção e posição estratégica no mercado internacional, segundo um relatório do IBGE (2004), sobre caracterização e cultivo de plantas ornamentais no Brasil. Além disso, IBGE (2004) também reporta que apenas $0,16 \%$ dos estabelecimentos agropecuários brasileiros amostrados tiveram alguma receita com a prática do cultivo e comercialização de plantas ornamentais. O comércio de plantas ornamentais no mundo movimenta aproximadamente US\$ 30 bilhôes ao ano, sendo a Holanda a líder de mercado, movimentando cerca de US\$ 3 bilhōes ao ano (Groot, 1999; IBGE, 2004). Ao apresentar estes valores não é pretendido tentar colocar as RESEXs em posição de competir com os grandes mercados internacionais, mas mostrar que plantas ornamentais podem se tornar um produto comercial, mesmo que para atender apenas ao mercado interno. $\mathrm{O}$ foco das RESEXs baseia-se na sustentabilidade e a comercialização das helicônias pode 
servir como complementação pela venda de um produto que já existe na área.

Em Manaus os valores praticados pelas floriculturas na venda de arranjos de helicônias variam em função da forma de obtenção do produto. As floriculturas que não cultivam as helicônias acabam repassando ao consumidor um valor duas vezes maior, em torno de US\$ 50,00. As exportaçôes de flores tropicais estão em expansão no Brasil, e em 2006 foi arrecadado US\$29,63 em exportações, $15,06 \%$ do que o ano anterior, sendo Holanda (ca. 50\%), Estados Unidos (ca. 20\%) e Itália (ca. 10\%) os principais compradores (Junqueira \& Peetz, 2007). No mesmo período, as helicônias ficaram em primeiro lugar em número de vendas, originadas principalmente de Pernambuco, Alagoas e Ceará (Junqueira $\&$ Peetz, 2007).

Estudos em longo prazo para determinar o real impacto da extração de produtos não-madeireiros são escassos na Amazônia, e devem estar previstos nas agendas dos gestores das RESEXs. A economia na forma do extrativismo praticado dentro das reservas florestais na Amazônia, mesmo acarretando em alguns impactos diretos sobre a fauna e a flora (Nepstad $e t$ al., 1992), garante a cobertura vegetal, ajudando a manter as funções ecológicas originais da floresta, evitando perdas futuras de biodiversidade regional (Moutinho, 2006). Adicionalmente, garante a continuidade das populaçôes tradicionais no campo, com efeito direto na economia local e regional.

\section{AGRADECIMENTOS}

Agradecemos a Soledad Novelle, Luiza P. Lopes, Maria Ermelinda Oliveira, Paulo Henrique Oliveira e Xênya Garcia pelo auxílio no trabalho de campo. João Marcelo Alvarenga Braga pela confirmação nas identificaçōes de algumas espécies de Heliconia. Agradecemos também aos dois revisores anônimos pelas valiosas sugestôes que enriqueceram muito o trabalho. IBAMA, Programa ARPA e FNMA pelo apoio financeiro e logístico. CAPES e IIEB (Programa BECA, B/2005/02/ BDP/06, Gordon and Betty Moore Foundation) pela bolsa concedida a R. Arruda; e FAPEAM pela bolsa concedida a V.T. Carvalho. Este trabalho é parte da tese de doutorado de R. Arruda, financiada pelo CNPq ("Biodiversidade Amazônica: Distribuição, biomassa, conservação e utilização", Processo 472799/03-7; "Distribuição da variabilidade genética de organismos amazônicos com potencial biotecnológico", Processo 553997/2006-8).

\section{BIBLIOGRAFIA CITADA}

Aristeguieta, L. 1961. El genero Heliconia en Venezuela. Editora Grafos C.A., Instituto Botanico, Dirección de Recursos
Naturales Renovables, Ministerio de Agricultura y Cría. Caracas, Venezuela. 61pp.

Athayde, S.F.; Silva, G.M.; Kaiabi, J.; Kaiabi, M.; Souza, H.R.; Bruna, E.M.; Ono, K. 2006.

Participatory management of "Arumã" (Ischnosiphon gracilis, Marantaceae) amongst the Kaiabi people in the Brazilian Amazon. Journal of Ethnobiology 26: 36-59.

Berry, F.; Kress, W.J. 1991. Heliconia: an identification guide. Smithsonian Institution Press, Washington and London. 334pp.

Goulding, M.; Barthem, R.; Ferreira, E. 2003. The Smithsonian atlas of the Amazon. Smithsonian Books, Washington and London. 253pp.

Groot, N.S.P. 1999. Floriculture worldwide trade and consumption patterns. Acta Horticulturae 495: 101-121.

Guimarães, A. 2001. Oportunidades de negócios na Amazônia: alternativas sustentáveis. In: Veríssimo, A.; Moreira, A.; Sawyer, D.; Santos, I.; Pinto, L.P.; Capobianco, J.P.R. (Eds). Biodiversidade na Amazônia Brasileira: avaliação e açôes prioritárias para a conservação, uso sustentável e repartição de beneficios. Instituto Socioambiental, São Paulo. p 60-78.

Hernández, M.I.S. 2004. Heliconias: Belleza y alternativa econômica para Tabasco. Revista Diálogos 5: 14-18.

Instituto Brasileiro de Geografia e Estatística (IBGE). 2004. Caracterização do setor produtivo de flores e plantas ornamentais no Brasil 1995-1996. IBGE, Rio de Janeiro. 78pp.

Junqueira, A.H.; Peetz, M.S. 2007. Las exportaciones brasileñas de flores y plantas crecen más del 124\% entre 2001 y 2006. Revista Horticultura Internacional 56: 76-79.

Kress, W.J.; Betancur, J; Echeverry, B. 1999. Heliconias - Llamaradas de la selva colombiana. Cristina Uribe Editores, Bogota. 200pp.

Moutinho, P. 2006. Biodiversidade e mudança climática sob um enfoque Amazônico. In: Rocha, C.F.D.; Bergallo, H.G.; Van Sluys, M.; Alves, M.A.S. (Eds). Biologia da Conservação: Essências. RiMa Editora, São Carlos. p 119-133.

Nakazono, E.; Bruna, E.M.; Mesquita, R.C.G. 2004. Experimental harvesting of Arumã (Ischnosiphon polyphyllus, Marantaceae), a nontimber forest product in the central Amazon. Forest Ecology and Management 190: 219-225.

Nepstad, D.C.; Brown, F.; Luz, L.; Alechandre, A.; Viana, V. 1992. Biotic impoverishment of Amazonian Forests by rubber tappers, loggers and catlle ranchers. Advances in Economic Botany 9: $1-14$.

Rodrigues, E.; Paula, A.C.; Araújo, C.M. 2004. Roteiros metodológicos: plano de manejo de uso múltiplo das reservas extrativistas federais. IBAMA, Brasília. 157pp.

Ticktin, T. 2004. The ecological implications of harvesting nontimber forest products. Journal of Applied Ecology 41: 11-21.

Recebido em 26/11/2007

Aceito em 14/08/2008 